\title{
PATRIMÔNIO COMO CATEGORIA DE LUTA LGBT+?
}

Julia Xavier Barros

Bruno Sanches R. da Silva

\section{RESUMO}

Para os propósitos deste resumo, partirei da concepção de patrimônio como uma categoria Estatal de gestão do espaço público e da memória social (SILVA 2017). Nesse escopo, gostaria de fazer algumas considerações sobre o uso dessa categoria como instrumento de luta, como retórica que possa carregar pautas sociais em negociação com o Estado pela melhoria da qualidade de vida da população - aqui, falo da população LGBT+. Veremos brevemente, ao final, o caso da Parada do Orgulho LGBT de São Paulo.

PALAVRAS-CHAVE: Patrimônio cultural; Movimento LGBT; Movimento social; Estado de bem-estar social; Políticas Públicas.

\section{ABSTRACT}

The basic premise of this article is that cultural heritage is as a State and legal category for the management of public space and social memory (Autor 2017). And so, I would like to make some considerations about the use of said category as an instrument for social development. Evaluating its capacity to represent social demands in negotiation with the State for the improvement of the life quality - here, I speak of the LGBT population. We will briefly discuss, in the end, the case of the LGBT Pride Parade in São Paulo.

KEYWORDS: Cultural heritage; LGBT movement; Social movement; Wellfare state; Public policies.

\section{RESUMEN}

Para los propósitos de este resumen, considero el patrimonio como una categoría Estatal de gestión del espacio público y de la memoria social (SILVA 2017). En ese ámbito, quisiera hacer algunas consideraciones sobre el uso de esa categoría como instrumento de lucha, como retórica que pueda llevar consigo pautas sociales al negociar con el Estado por la mejora de la calidad de vida de la población - aquí, hablo de la población LGBT+. Veremos brevemente, al final, el caso de la Parada del Orgullo LGBT de São Paulo.

PALABRAS-CLAVE: Patrimonio cultural; Movimiento LGBT; Movimiento social; Estado de bien estar social; Políticas Públicas.

\section{INTRODUÇÃO}

Atualmente, o Brasil tem presenciado um crescimento massivo do conservadorismo. Observa-se $\mathrm{o}$ aumento de bancadas aliadas a grupos religiosos intolerantes à diversidade $\mathrm{e}$ 
outras agendas em favor de minorias, o que ameaça as conquistas de direitos das minorias realizadas nas últimas décadas e oblitera as discussões ocorridas no campo do gênero e da sexualidade através de iniciativas programas como o "Escola sem Partido", condenando o que chamam de "ideologia de gênero", e o vilipendiamento da educação sexual pelo pela alcunha do "Kit gay", assim como ameaça a laicidade do Estado (especialmente vindas do MEC e do recém-criado MDH). A eleição do atual presidente, Jair Messias Bolsonaro, que fere diversas minorias com opiniões até então insustentáveis para um líder de Estado, é um sintoma claro da escalada da intolerância e conservadorismo no país. Diante dessa onda que se instaurou nos últimos anos os movimentos sociais devem criar estratégias para combater as violências e opressões sofridos em seu dia a dia.

A estratégia de patrimonialização da parada do Orgulho LGBTQ+ em São Paulo é uma tentativa dos agentes envolvidos para obter mais visibilidade, 0 ato de tornar patrimônio é utilizada por muitos grupos minoritários, a fim de aumentar sua visibilidade e para garantir algum tipo de proteção junto ao Estado. Miskolci (2011) relata que a expansão do movimento LGTBQ+ no Brasil teria se dado junto ao Estado, portanto, é compreensível que tal estratégia de patrimonialização seja adotada.

A Constituição Federal de 1988 trouxe a ampliação da ideia de patrimônio cultural, passando a reconhecer tanto o patrimônio material como o imaterial. Data de 4 de agosto de 2000 o Decreto no 3.55, que institui o Registro de Bens Culturais de Natureza Imaterial e o Programa Nacional do Patrimônio Imaterial. Ainda de acordo com o decreto os pedidos de registro devem ser dirigidos ao presidente do Instituto do Patrimônio Nacional que o encaminha para o Conselho Consultivo do Patrimônio Cultural, ou no caso da cidade de São Paulo, dirigidas ao Conselho Municipal de Preservação do Patrimônio Histórico, Cultural e Ambiental da Cidade de São Paulo - CONPRESP.

Neste cenário, o patrimônio como categoria jurídica de gestão do pública do espaço e memória social move uma condição essencial nas pautas LGBT+: identidades. $O$ patrimônio como representação (VASCONCELLOS, 2013; SILVA, 2017) se converte em instância que mobiliza, congrega, sedimenta e reproduz formas de identidade importantes para a constituição dos sujeitos sociais (BEZERRA, 2011; GONÇALVES, 2015). Para tentar atender à multiplicidade de origens e processos socioculturais, e responder às demandas dos Movimentos civis, o Estado brasileiro tem criado categorias e normativas para proteção e valoração de expressões humanas pelo patrimônio, sendo os principais o Decreto-Lei no 
25 de 1937 (Tombamento de bens materiais), Lei no 3.924 de 1961 (Proteção dos sítios arqueológicos pré-históricos), Resolução CONAMA № 001 de 1986 (Instaura o Estudo e Relatório de Impacto Ambiental, contemplando arqueologia, para licença de empreendimentos), bem como o já mencionado Decreto.

Em 2017, é apresentado à Câmara dos Vereadores de São Paulo/SP o Projeto de Lei no 399/2017, que busca registrar a Parada do Orgulho LGBT+ da cidade como patrimônio imaterial. O que pretendemos abordar com esse artigo é: a patrimonialização pode ser uma estratégia viável para a defesa de causas da comunidade?

\section{BREVE HISTÓRIA DO MOVIMENTO LGBTQ+ NO BRASIL}

O chamado movimento homossexual tem sua trajetória iniciada no final dos anos 70 . Essa atuação é marcada por um forte caráter antiautoritário, crítica ao Estado e valorização da figura de gays e lésbicas (FACCHINI, 2009), além do questionamento da hierarquização dos papéis em relacionamentos do mesmo sexo (FRANÇA, 2006). É interessante apontar a influência do movimento feminista no meio homossexual, como o faz Peter Fry (1982) ao lembrar que essa revisão de papéis, especialmente em condição conjugal, provém do esforço feminista em romper com dominação masculina no ambiente doméstico e vida pública.

A década de 80 foi marcada por uma maior articulação junto ao Estado, devido a luta contra a AIDS, que também trouxe certo estigma para os homossexuais (FACCHINI, 2009). A atuação do movimento passa a ser mais prática, se voltando à garantia de direitos civis e luta contra discriminações e violências, bem como a humanização de homossexuais.

Nos anos 90 observa-se uma expansão em relação ao combate a homofobia e combate ao HIV através de diferentes formatos institucionais adotados pelo movimento, assim como maior articulação internacional (SIMÕES, 2002). As ações que possuíam um caráter mais comunitário e não tão próximas do Estado vão se estruturando de maneira cada vez mais formal e burocrática, com papéis fixos de seus integrantes, busca por financiamentos e participação de órgãos governamentais próximos do modelo de uma organização não governamental (SIMÕES, 2002). Essa aproximação com o Estado traz, 
durante a chamada redemocratização, uma ampliação da participação em candidaturas e projetos de lei, os partidos são utilizados para que as demandas do movimento sejam percebidas e postas em prática, com a presença de setoriais em partidos como o PT e PSTU, dentre outros (FACCHINI, 2009). Uma estratégia amplamente adotada para ampliar a visibilidade do movimento foi a organização das Paradas do Orgulho LGBT+ (FACCHINI, 2009). É também nos 90 que ocorre uma reconfiguração dos espaços de liberdade da comunidade, que passam a incorporar o discurso político de visibilidade e orgulho, se utilizando de símbolos como a bandeira do arco-íris (FRANÇA, 2006).

A partir dessas mudanças na esfera política passam a surgir mais iniciativas como Plano Nacional de Educação em Direitos Humanos e o programa federal Brasil sem Homofobia: programa de combate à violência e à discriminação contra LGBT+ e promoção da cidadania homossexual no primeiro mandato de Lula e a nível municipal como as prefeituras de Belo Horizonte, Fortaleza e São Paulo criam Coordenadoria de Assuntos da Diversidade Sexual dentro de suas respectivas Secretarias de Direitos Humanos, no caso de Belo Horizonte e de Fortaleza e Secretaria de Participação e Parcerias no caso paulista (SILVA, 2011).

Destaca-se que ano de 2008 acontece a primeira conferência nacional LGBT+, sendo o Brasil o primeiro país a sinalizar um compromisso de Estado com uma política a favor dos direitos da sigla (FACCHINI, 2009). Em sua abertura contou com a presença do então presidente Luiz Inácio Lula da Silva, ministros e líderes do movimento. A segunda conferência nacional se deu em 2011, durante o governo da presidenta Dilma Rousseff. As conferências nacionais e outras iniciativas de participação social fizeram parte do projeto do governo Lula-Dilma para elaborar políticas de afirmação para grupos minoritários (AGUIÃO, 2016), com 85 conferências realizadas nesse período, de um total de 126 desde a década de 40 (AVRITZER, 2013).

Diante dessa trajetória podemos tecer algumas críticas, seja na atuação do Estado em relação às políticas públicas adotadas em favor da população LGBT+ como ao próprio movimento sua atuação e pautas adotadas principalmente ao longo da última década. Por exemplo o governo Lula-Dilma falhou na instauração de um programa de educação sexual sobre educação sexual, diante de uma forte oposição no Congresso e pelo público. A escalada do conservadorismo no Brasil nos últimos anos pode ser atribuída também pelo 
fato da esquerda, que levava em diante tais pautas, ter falhado em romper com uma oposição conservadora.

\section{PATRIMÔNIO COMO CATEGORIA DE LUTA LGBT+?}

Nesse momento, uma posição necessária: entendemos patrimônio como uma categoria jurídica, um modelo de origem estatal para o controle do espaço e memória coletiva. Por mais que usemos essa palavra para transmissões hereditárias de bens familiares, ou mesmo para identificar bens (individuais ou coletivos) que nos conectam com o tempo, para além do imediato, devemos lembrar que dar início a um processo de patrimonialização (seja tombamento de bens materiais ou registro de bens imateriais) significa dialogar diretamente com o Estado.

Essa constatação é importante para não confundirmos os interesses do Estado com os interesses civis pelo patrimônio. A proposta desta apresentação é justamente buscar entender se há uma relação possível entre o Estado e a comunidade LGBT+ brasileira pela categoria do patrimônio.

O Estado é uma entidade, no mínimo, polêmica. Ao menos no Estado no caso brasileiro, temos uma entidade dividida em três poderes (Executivo, Legislativo e Judiciário) que devem manter-se equilibrados e zelar pelos interesses do coletivo que representam. Ao mesmo tempo, é uma entidade que nunca atua contra si mesma (SOUSA, comunicação pessoal 2017). Ela tem, por exemplo, jurado muito em nome de Deus, da família e do povo brasileiro. Mas o Estado brasileiro, atrelado a uma Lei da Anistia também polêmica, só construiu uma Comissão Nacional da Verdade, para apurar os crimes da Ditadura Militar (1964 - 1986) após ser condenado pela Corte Internacional ${ }^{1}$.

Nesse panorama, vale lembrar outra obviedade. Esse mesmo Estado brasileiro polêmico, se comprometeu a promover o respeito à diversidade étnica, sexual e de gênero, pela Constituição Federal de 1988, como vemos no artigo 3ํㅗ IV, que:

${ }^{1}$ https://brasil.elpais.com/brasil/2014/05/22/internacional/1400766899_687225.html

\begin{tabular}{|l|c|c|c|c|c|}
\hline () Rev. Arqueologia Pública & Campinas, SP & v.13 & n.1 & p. & Jul/2019
\end{tabular} ISSN 2237-8294 
"Art. $3^{\circ}$ Constituem objetivos fundamentais da República Federativa do Brasil:

(...)

IV - promover o bem de todos, sem preconceitos de origem, raça, sexo, cor, idade e quaisquer outras formas de discriminação."

Mesmo que ela tenha sofrido traumas com o Golpe de 2016, a força dos inúmeros Movimentos Sociais (Negros, Feministas, LGBT+, Indígenas, Quilombolas, Ribeirinhos, Agricultores familiares) continua pulsando com as lutas pelo reconhecimento e respeito aos múltiplos modos de vida em nosso país.

Sobre as questões que tangem as causas LGBT+, acredito que dois vacilos gigantescos do Estado nos últimos tempos devam ser mencionados. O primeiro foi a incapacidade do governo PTista de romper com a oposição e inaugurar políticas educativas contra a homofobia no ensino público básico. A oposição gentilmente apelidou o material didático associado como "kit gay" ${ }^{2}$ deixando clara sua ideia de que educar contra a homofobia significa transformar todo mundo em viado. E que isso é um problema. Por que, né?... "Não tenho nada contra gay e lésbica, mas...".

Outro deles tem sido o Projeto "Escola Sem Partido", que circula (e foi sancionado) por vários Estados e municípios do Brasil. Os autores legislativos são, em totalidade, de partidos de alinhamento neoliberal conservador (uma esquizofrenia bastante antiga e conhecida entre nosotros hermanos). A saber, a proposta do Projeto é, na cara dura, uma educação que não seja crítica, apenas transmissora de conhecimento. Polêmico. E se propõe, de modo hipócrita, "apartidário" e "sem ideologia".

Uma breve nota: no Brasil, "comunista" e "ideologia" se tornaram novos jargões usados pela classe média/alta para identificar a oposição. Foi um setor que ingressou na sociedade de consumo em larga escala, como um resultado de políticas de controle Estatal de juros e preços pelo próprio governo que, 13 anos depois, ajudaram a derrubar. $O$ acesso aos bens de consumo, aparentemente, não os ajudou a comprar (ou acessar gratuitamente, através dos planos de internet telefônica), livros e artigos que explicassem o que significa "comunismo" e "ideologia".

2 http://g1.globo.com/educacao/noticia/2011/05/projeto-de-distribuir-nas-escolas-kits-contrahomofobia-provoca-debate.html

\begin{tabular}{|l|l|l|l|l|l|l|}
\hline (C) Rev. Arqueologia Pública & Campinas, SP & v.13 & n.1 & p. & Jul/2019 & ISSN 2237-8294 \\
\hline
\end{tabular}


Desabafo à parte, a justificativa apresentada junto ao Projeto de Lei ํㅜ 867, de 2015, segue:

É fato notório que professores e autores de livros didáticos vêm-se utilizando de suas aulas e de suas obras para tentar obter a adesão dos estudantes a determinadas correntes políticas e ideológicas; e para fazer com que eles adotem padrões de julgamento e de conduta moral especialmente moral sexual - incompatíveis com os que lhes são ensinados por seus pais ou responsáveis. (grifo meu)

Considerados esses vacilos, acho que também é fundamental lembrarmos que não se tratam apenas de "deslizes" de uma Instituição metida à onipresença. Mas sim, o esforço direcionado de setores e agentes sociais contrários às pautas da diversidade, uma vez que viver com dignidade significa que cada vida, cada coletivo, tem poder sobre si. E, para isso, as autarquias centrais precisam abrir mão de seus próprios poderes sobre os corpos e vidas alheias.

Com isso viabilizamos também o caminho para nossa própria tomada de poder, uso do aparelho estatal para cumprimento de seu, pelo menos teórico, desígnio social.

Com essas breves considerações sobre a arte do Estado, voltamos às perguntas iniciais: como nós, LGBT+, enquanto agentes humanos, podemos fazer valer o dever Estatal de promover o respeito às diversidades? Seria o patrimônio uma saída possível?

O patrimônio como categoria jurídica de gestão pública do espaço e memória social move uma condição essencial nas pautas LGBT+: identidades. O patrimônio como representação (VASCONCELLOS, 2013; SILVA, 2017) se converte em instância que mobiliza, congrega, sedimenta e reproduz formas de identidade importante para a constituição dos sujeitos sociais (BEZERRA, 2011; GONÇALVES, 2015). Para tentar atender à multiplicidade de origens e processos socioculturais, e responder às demandas dos Movimentos civis, o Estado brasileiro tem criado categorias e normativas para proteção e valoração de expressões humanas pelo patrimônio, sendo os principais o Decreto-Lei no 25 de 1937 (Tombamento de bens materiais), Lei no 3.924 de 1961 (Proteção dos sítios arqueológicos pré-históricos), Resolução CONAMA № 001 de 1986 (Instaura o Estudo e Relatório de Impacto Ambiental, contemplando arqueologia, para licença de empreendimentos) e Decreto no 3.551 de 2000 (registro de patrimônio imaterial). 
Em 14 de junho de 2017, ingressou na Câmara de Vereadores de São Paulo, o Projeto de Lei no 399/2017, de autoria da vereadora Sâmia Bonfim (PSOL) e do Vereador Eduardo Suplicy (PT), que propunha o "reconhecimento da Parada do Orgulho Gay de São Paulo como patrimônio imaterial da cidade". O evento em pauta é a maior Parada do Orgulho LGBT+ do mundo ${ }^{3}$ e busca carregar nas ruas da maior cidade da América Latina, a bandeira da diversidade.

Através do sítio de internet da Câmara (http://www.camara.sp.gov.br/atividadelegislativa/splegis-consulta/) foi possível ter acesso à integra de toda documentação gerada sobre o processo. De forma sumária, ele correu dentro dos prazos regimentais normais. Ao PL foi dado parecer negativo - pelas instâncias consultoras do poder executivo (Diretoria do Patrimônio Histórico/Secretaria Municipal de Cultura e Procuradoria Municipal), alegando caber ao Executivo, não cabe ao legislativo, o registro de bens culturais imóveis. A última movimentação averiguada, dia 01 de junho de 2018, o processo já havia retornado à Câmara, para a Comissão de Constituição e Justiça, relatado e aguarda seguimento para a Plenária e, dado à negativa, será provavelmente arquivado.

A justificativa do Projeto de Lei menciona a relação formulada entre o evento, realizado no mês de junho, e o conhecido marco internacional da luta pelos direitos LGBT+'s: a Stonewall Riots, de 28 de junho de 1969. Reconhece também:

\begin{abstract}
A Parada é hoje um evento estratégico da visibilidade dos direitos LGBTs, e tem se revelado uma importante ação coletiva de cunho político, enquanto instrumento de participação social e na sociedade contemporânea, através da visibilidade que conquistou no espaço público e das questões que através dela emergem como tematizações da própria sociedade brasileira.
\end{abstract}

Menciona também um atributo frequentemente coringa para qualquer requerimento (especialmente administrativos):

Estudos do Observatório do Turismo indicam que cada participante da Parada do Orgulho LGBT, que tem em média 3 milhões de participantes, deixam cerca de $R \$ 1.200,00$ reais na cidade, somando mais de 3 bilhões de reais circulando durante o evento.

3 https://www.huffpostbrasil.com/2017/06/17/7-fatos-que-tornam-a-parada-do-orgulho-lgbt-de-saopaulo-a-mel_a_22372250/

\begin{tabular}{|l|l|l|l|l|l|l|}
\hline (C) Rev. Arqueologia Pública & Campinas, SP & v.13 & n.1 & p. & Jul/2019 & ISSN 2237-8294
\end{tabular}


A Parada de São Paulo tornou-se um evento não apenas de visibilidade, mas também de rendimento financeiro, com patrocinadores e propagandas de peso. A página do Instagram do evento publica sua parceria com a Microsoft e Arcor Hotéis. Em 2017, a Uber contratou um trio elétrico, após o escândalo de assédio sexual na empresa que levou à 20 demissões (incluindo-se membros da diretoria) ${ }^{4}$.

O Pink Money e outras formas de homonormatividade (como a reprodução de misoginia e racialização dentro das comunidades gay) são pauta dentro dos movimentos LGBT+'s, uma vez que, sabemos, o heteropatriarcado que nos oprime está ontologicamente ligado ao sistema capitalista. E nesse escopo que os debates sobre representação se encontram com a ideia de patrimônio (e por essa mesma razão que devemos entender como funciona o patrimônio) - qual comunidade LGBT+ queremos representar? Quais pautas queremos levar às ruas e "imortalizar" como bem cultural da nação? Até o momento, a Parada o único caso de patrimônio imaterial a representar a comunidade LGBT+ no Brasil.

De acordo com a PL e com reportagens sobre a empreitada, a iniciativa partiu de uma parceria da legisladora, legislador e da Associação da Parada do Orgulho LGBT+ de São Paulo. Infelizmente, não consegui ter acesso a nenhum desses três atores (e devo assumir mea culpa, pois busquei contato em cima da hora). Mas enviei-lhes questionários para saber um pouco mais de suas experiências com o processo, seu significado, objetivos e também se tiveram acesso a consultoria especializada sobre patrimônio e sua legislação [a resposta à essa última, imagino, seria negativa. Um profissional do patrimônio no Brasil teria dito que aquele não era o caminho apropriado para alcançar a intenção desejada].

Sobre patrimônio e construção de formas de representação, podemos adentrar tranquilamente em nossa esfera de atuação: a arqueologia. Essa disciplina tem atuado de modo direto ou indireto, consciente ou inconscientemente, na criação de modos de vida através de suas narrativas sobre o passado (DÍAZ-ANDREU, 2002; FERREIRA, 2013). Ao longo dos anos, a consciência desse processo significou uma nova "perda da inocência" (parafraseando CLARKE, 1973). No Brasil e imagino que em outros lugares da América Latina, essa consciência foi fruto de viradas teóricas, mas de muito mais importância foi a pressão dos movimentos sociais, com quem a arqueologia teve que dialogar diretamente

${ }^{4}$ https://brasil.elpais.com/brasil/2017/06/16/politica/1497625885_659787.html

\begin{tabular}{|l|l|l|l|l|l|l|}
\hline (C) Rev. Arqueologia Pública & Campinas, SP & v.13 & n.1 & p. & Jul/2019 & ISSN 2237-8294 \\
\hline
\end{tabular} 
como consequência de seu ingresso no licenciamento ambiental nos anos 1980. Como consequência direta do exercício de arqueólogas e arqueólogos como responsáveis legais pela proteção do patrimônio arqueológico da União (CONAMA 1986, Lei no 3924/61).

As arqueologias feministas, queer e estudos de gênero ainda precisam ocupar um espaço maior no âmbito nacional. Em 2017, foi publicado, sob a coordenação de Loredana Ribeiro, um estudo sobre a presença do tema e da relação entre autorEs e autorAs, nos Planos Curriculares de 10 das 13 graduações brasileiras em arqueologia, bem como nos Programas de Pós-Graduação da área de sete Universidades em nosso país (RIBEIRO et al. 2017). O resultado, em suma, mostra uma grande lacuna temática nos programas de graduação e pós e da menor presença de autoras mulheres (mesmo sendo as que mais publicam sobre arqueologia no Brasil).

Nada se compara, todavia, à raridade com que autoras e/ou textos feministas são indicados nos PPCs. Das mais de quatro mil e duzentas ocorrências contabilizadas, apenas 21(!) são obras ligadas à gênero e teorias feministas e aparecem em seis dos dez PPCs. Quatorze indicações são específicas de arqueologia e aparecem em seis disciplinas, quatro obrigatórias e duas optativas (...). Nenhum dos títulos se repete, e a seleção é ampla, incluindo de panorâmicas sobre a trajetória da temática no campo da arqueologia a estudos de caso e discussões teóricas (RIBEIRO, SILVA, SCHMIDT e PASSOS, 2017, p. 1103).

Assim, como já é de costume em outras ciências humanas, a arqueologia pode contribuir muito com o debate acima, bem com as pautas identitárias e libertárias da comunidade LGBT+. Na história e antropologia, por exemplo, o estudo da diversidade ao longo do tempo e espaço tem servido para desnatuzalizar relações sociais de gênero, sexualidades e políticas sobre os corpos.

Para citar um exemplo nacional, Renato Pinto é um dos pioneiros na aplicação da teoria queer e pauta LGBT+ no Brasil. Em 2011, defende sua tese de doutorado sobre a construção da masculinidade burguesa na Inglaterra do século XIX, usando de atributos de virilidade da Roma em seu apogeu imperial. Entre os capítulos da tese, está o caso de um sepultamento encontrado em Catterick, Inglaterra, com provável data do século IV d.C. A ossada foi identificada, pela morfologia, como do sexo masculino, mas com uma indumentária feminina (associada ao culto da deusa Cibele). Renato trabalha, também, como a reconstituição arqueológica do indivíduo sepultado foi apropriado pelo movimento trans na Inglaterra. 
Para finalizar, acredito que este cenário será muito incrementado nos próximos anos, partindo também de um movimento de base nas universidades: as e os estudantes de graduação. As políticas de ações afirmativas implementadas pelo Governo Federal nos últimos 10 anos têm reconfigurado o coletivo estudantil e, por tabela, o docente. Cada vez mais estudantes de periferias urbanas, indígenas, quilombolas, ribeirinhos, homoafetivos, trans, compõe as turmas de ingressantes. Não têm sido fácil, certamente. Estruturada em uma sociedade dominada pelo heteropatriarcado, muitas e muitos têm sofrido para conseguir permanecer e vencer os preconceitos. Mas a Universidade, com isso, se vê obrigada a mudar por dentro. E a arqueologia, como uma disciplina institucionalizada desde o século XIX, hoje com 15 cursos universitários de graduação, já vem sendo questionada do mesmo modo.

Estado à parte, estamos vives e não seremos invisibilizades.

Amém, Axé, Surara e Força na Peruca!

\section{REFERÊNCIAS BIBLIOGRÁFICAS}

BEZERRA, Márcia. "As moedas dos índios": um estudo de caso sobre os significados do patrimônio arqueológico para os moradores da Vila Joanes, ilha de Marajó, Brasil. Boletim do Museu Paraense Emilio Goeldi. Ciências Humanas. Vol. 6, no 1. 2011. Pp. 5770.

CLARKE, David. Archaeology: the loss of innocente. Antiquity. Vol. 47, no 185. 1973. Pp. 6-18.

DÍAZ-ANDREU, Margarita. Nacionalismo e arqueologia: o contexto político da nossa disciplina. Revista Aulas. № 2. 2002.

FACCHINI, Regina, FRANÇA, Isadora. Convenções de gênero, sexualidade e violência: pesquisa com participantes dos eventos do Orgulho LGBT de São Paulo. 2009. Latitude. Vol. 7. 2013. Pp. 11-30.

FRANÇA, Isadora. “Cada macaco no seu galho?": arranjos de poder, políticas identitárias e segmentação de mercado no movimento homossexual. Revista Brasileira de Ciências Sociais. São Paulo. v. 21, n. 60. 2006. p. 103-115.

FRY, Peter. Da hierarquia à igualdade: a construção histórica da homossexualidade no Brasil. In: . Para inglês ver: identidade e política na cultura brasileira. Rio de Janeiro: Zahar. 1982. p. 87-115. 
FERREIRA, Lucio Menezes. La arqueología siempre fue pública. In: SALERNO, V. Arqueologia pública: reflexiones sobre la construcción de un objeto de estudio. Revista Chilena de Antropologia. Vol. 27. 2013. pp. 7-37.

GONÇALVES, José Reinaldo. O mal-estar do patrimônio: identidade, tempo e destruição. Estudos Históricos. Vol. 28, № 55, 2015. Pp. 211-228.

MISKOLCI, Richard. Não somos, queremos - reflexões queer sobre a política sexual brasileira contemporânea. In: COLLING, Leandro. Stonewall 40 + o que no Brasil? Salvador: EDUFBA. 2011. p. 37-56.

PRECIADO, Beatriz. "Multidões queer: notas para uma política dos 'anormais"”. Revista Estudos Feministas. Vol. 19, n. 1. jan./abr. 2011. p. 11-20.

RIBEIRO, Loredana, SILVA, Bruno S. R. da, SCHMIDT, Sarah K.; PASSOS, Lara. A Saia Justa da Arqueologia Brasileira: mulheres e feminismos em apuro bibliográfico. Revista Estudos Feministas. Vol. 25, № 3. 2017. Pp. 1093 - 1110. doi:http://dx.doi.org/10.1590/1806-9584.2017v25n3p1093.

VASCONCELLOS, Camilo de Mello (2013). Patrimonio, memoria y educación: una visión museológica. Memória y Sociedad. Vol. 17, no 35. 2013. pp. 94-105. Fonte: http://www.scielo.org.co/pdf/meso/v17n35/v17n35a06.pdf.

SIMÕES, Júlio Assis. Prefácio. In: "Sopa de Letrinhas"? Movimento homossexual e produção de identidades coletivas nos anos 90: um estudo a partir da cidade de São Paulo. Tese de mestrado, Campinas, Universidade de Campinas, IFCH mimeo. pg 13 - 19. 2002.

SILVA, Alessandro Soares. Por um Lugar ao Sol: construindo a memória Política da homossexualidade (ou: Homossexualidade: uma história dos vencidos?!). Bagoas: Revista de Estudos Gays. Vol. 6. 2012. p. 77-102. 